\title{
Reconhecimentos: com Paul Ricoeur e Axel Honneth'
}

\author{
Recognitions: with Paul Ricoeur and Axel Honneth
}

\section{Laurent Thévenot}

Laurent Thévenot é professor emérito (Diretor de estudos) na l'École des Hautes Etudes en Sciences Sociales, em Paris/França. Junto a Luc Boltanski, desenvolveu a guinada pragmática na sociologia francesa (De la justification. Les économies de la grandeur, 1991; em inglês: On justification: economies of worth, 2006). O autor fundou junto a economistas, a corrente institucionalista crítica da "teoria das convenções". Mais recentemente, identificou outras construções do comum e do plural (gramática liberal dos interesses, gramática das afinidades pessoais aos lugares-comuns) e diversos modos de envolvimento que conferem coerência e dinamismo à comunidade è personalidade, o que permite avançar na análise crítica do poder e da opressão (L’action au pluriel: sociologie des régimes d’engagement, 2006; em espanhol: La acción en plural. Una introducción a la sociología pragmática.

\section{Tradução de Fabio Reis Mota, Yolanda Gaffrée Ribeiro e Daniela Vélasquez}

\section{Fabio Reis Mota}

Professor do Departamento de Antropologia e do Programa de Pós-Graduação em Antropologia da Universidade Federal Fluminense (UFF). Coordenador do Núcleo Fluminense de Estudos e Pesquisa (Nufep). Pesquisador do Instituto Nacional de Estudos Comparado em Administração Institucional de Conflitos (INCT/InEAC/UFF).

\section{Yolanda Gaffrée Ribeiro}

Doutora em Antropologia. Pós-doutoranda (Capes/INCT/InEAC/UFF) no Programa de Pós-Graduação em Antropologia da Universidade Federal Fluminense (UFF). Pesquisadora do Núcleo Fluminense de Estudos e Pesquisa (Nufep) e do Instituto Nacional de Estudos Comparados em Administração Institucional de Conflitos (INCT/InEAC/UFF).

\section{Daniela Vélasquez}

Doutoranda em Antropologia pelo Programa de Pós-Graduação em Antropologia da Universidade Federal Fluminense (UFF). Pesquisadora do Núcleo Fluminense de Estudos e Pesquisa (Nufep) e do Instituto Nacional de Estudos Comparados em Administração Institucional de Conflitos (INCT/ InEAC/UFF).

\footnotetext{
[Nota dos Tradutores] Este texto foi redigido originalmente para um volume dedicado ao diálogo de Paul Ricoeur com as Ciências Humanas, publicado em: DELACROIX, Christian; DOSSE, François; GARCIA, Patrick. (org.). Paul Ricœur et les sciences humaines. Paris: La Découverte, 2007. p. 127-143. Posterior a esta publicação, a caixa que se encontra no texto foi adicionada para a sua publicação em: CAILLÉ, Alain. (org.). La quête de reconnaissance: regards sociologiques. Paris: La Découverte, 2007. p. 269-283.
} 


\section{Resumo}

No estudo das relações de outros e de si mesmo que pretende levar em consideração a pessoa e não apenas a equivalência requerida pela demanda de justiça, quais são os pontos de convergência e divergência entre as concepções de Axel Honneth e Laurent Thévenot? A perspectiva sintética sobre o tema, a qual Paul Ricoeur oferta em seu livro Percursos do reconhecimento propõe ampliar um debate desses autores acrescido pela importante contribuição da filosofia que os precedeu nesse caminho.

Palavras-chave: Reconhecimento, Axel Honneth, Paul Ricoeur.

\section{Abstract}

In the study of the relations of others and of oneself that intends to take into account the person and not only the equivalence required by the demand for justice, what are the points of convergence and divergence between the conceptions of Axel Honneth and Laurent Thévenot? The synthetic perspective on the subject, which Paul Ricoeur offers in his book The course of recognition, proposes to broaden a debate of these authors added by the important contribution of the philosophy that preceded them in this path.

Keywords: Recognition, Axel Honneth, Paul Ricoeur.

Qual seria o tema mais adequado para exprimir a gratidão referente às considerações no diálogo extremamente generoso que Paul Ricoeur estabeleceu com as Ciências Sociais, senão aquele do reconhecimento?

No luminoso Percurso do Reconhecimento, Paul Ricoeur finalmente nos apresenta um prazeroso convite à imersão ao seu terceiro estudo, no qual discute articuladamente a reatualização do argumento de Hegel, nos moldes propostos por Axel Honneth, para distinguir as esferas do reconhecimento em seu livro A luta pelo reconhecimento (HONNETH, 2002²), e o reconhecimento pela "estima social" de acordo com o modelo das ordens de

\footnotetext{
[N. T.] As referências bibliográficas deste artigo se referem às edições das obras no francês. No caso de A luta pelo reconhecimento, a obra foi traduzida ao português por Luiz Repa, e publicada pela editora 34 no ano de 2003.
} 
grandeza desenvolvido por Luc Boltanski e eu mesmo no livro De la justification (BOLTANSKI; THÉVENOT, 1991³).

Seguirei aqui esse diálogo sem permanecer apenas num nível da estima social. Após a modelização das grandezas e suas provas ${ }^{4}$ de qualificação, pretendo esboçar os três regimes de envolvimento (ver o Quadro 1) que permitem decompor a arquitetura da vida em comum (THÉVENOT, 2006). Num encontro a três vozes, cujo alicerce é o texto grandioso de Ricoeur, sugerirei uma confrontação entre as três esferas do reconhecimento de Honneth e os três modos de reconhecimento que se fundamentam nos referidos regimes de envolvimento. As similitudes aparecem de fato, termo à termo, nas tripartições: $1^{\text {a }}$ parte - a confrontação aberta por Ricoeur entre grandeza e estima social; $2^{\text {a }}$ parte - incorporarei duas outras, respectivamente, fundadas sob o envolvimento no plano [engagement en plan] e a esfera do indivíduo racional conformado pela apreensão do direito; $3^{\text {a }}$ parte - explorarei o envolvimento familiar [engagement familier] e a esfera das relações amorosas e familiares. Dentro dos limites incumbidos a este texto, enquadrar-me-ei em determinadas chaves úteis à comparação. As observações liminares viabilizarão a emergência das diferentes escolhas formuladas pelos atores quanto ao tratamento da pessoa e da linguagem.

Quadro 1 - Diferenciar os regimes de envolvimento no mundo

A conformação da vida com os outros supõe o reconhecimento de uma diferenciação significativa entre as relações intimamente personalizadas quanto ao mundo que nos envolve e aquelas que requerem a construção

Continua...

3 [N. T.] Livro recentemente traduzido para o espanhol por Gabriel Nardacchione: Thévenot, L., 2016, La acción em plural. Una introducción a la sociologia pragmática.

${ }^{4}$ [N.T.] No original, “épreuves”, que no francês é um termo polissêmico, definindo tanto testes de resistência, de qualidade ou de conhecimento. Além disto, no âmbito da sociologia pragmática francesa, o termo "épreuve" é inserido como um conceito posto que esta vertente teórica pode ser também concebida como uma "Sociologia das provas". Para mais sobre o assunto ver: YANNICK, Bathe; BLIC, Damien de; HEURTIN, Jean-Philippe; LAGNEAU, Éric; LEMIEUX, Cyril; LINHARDT, Dominique; BELLAING, Cédric Moreau; RÉMy, Catherine; TROM, Danny. Sociologie Pragmatique: mode d'emploi. Politix: Revue des Sciences Sociales du Politque, n. 103, p. 175-204, 2013. 
do comum. As tensões que resultam dessa relação se revelam mais radicais do que as apreendidas através das oposições tradicionalmente mobilizadas entre indivíduo e coletivo, ou entre público e privado. De modo a melhor distinguir essas relações dinâmicas no (e com o) mundo, tais quais são reconhecidas nas expectativas diferenciadas dos atores, proponho uma noção de regime de envolvimento ${ }^{5}$ colocando em relevo seus traços característicos:

- A dependência do gênero de capacidade reconhecida ao agente, a respeito da realidade engajada no meio ambiente real, está moldada de acordo com essa capacidade que permite que o mesmo aposte, experimente e prove de maneira significativa ao se colocar à prova da realidade;

- O bem reconhecido como benefício dessa dependência, o qual visa garantir o envolvimento e que orienta a seleção e apreciação dos reparos pertinentes na dinâmica de experimentação ${ }^{6}$ do regime.

A noção de envolvimento permite apreender os regimes intimamente personalizados, bem como as disposições das pessoas e das coisas requeridas pelas formas de se envolver no mundo, reequilibrando o lugar do agente competente com relação ao agenciamento de capacidades evidenciando as boas e más experimentações do exercício da capacidade.

Cada um de nós saberia reconhecer esse gênero de relação com o mundo que eu defino como regime de envolvimento familiar. A capacidade da pessoa com relação ao mundo familiar depende do acomodamento,

\footnotetext{
[N.T.] No original, o conceito mobilizado é o de "régime d’engagement". Optamos por traduzir a palavra "engagement" como envolvimento, dada a acepção, na língua portuguesa, da palavra engajamento no sentido de uma participação política e/ou militante, a qual limitaria o sentido do conceito, que se propõe a ser mais abrangente. Para saber mais sobre o assunto, ver: CEFAÏ, Daniel; MELLO, Marco Antônio; MOTA, Fábio Reis; VEIGA, Felipe Berocan (org). Arenas Públicas: por uma etnografia da vida associativa. Niterói: Eduff, 2011; MOTA, Fabio Reis. Cidadãos em toda parte ou cidadãos à parte. Demandas de direitos e reconhecimento no Brasil e na França. Rio de Janeiro: Consequência, 2014; RIBEIRO. Yolanda G. Agentes políticos, especialistas e territórios de direitos: "os remanescentes de quilombo" no Rio de Janeiro e os "descendentes de imigrantes" em Paris. 2017. Tese (Doutorado em Antropologia) Universidade Federal Fluminense, Niterói, 2017.

6 [N.T.] No original, éprouvante. Optamos por traduzir “éprouvant(e)", ora como "experimentação", ora em sua acepção mais literal na língua francesa, como algo "penoso", "difícil" ou "extenuante", o que permite, do nosso ponto de vista, uma melhor compreensão do conceito em língua portuguesa, em cada caso.
} 
mediante os diversos arranjos pessoais, do círculo de proximidade. Cada um reconhece o bem que o conforta e que garante esse envolvimento que permite selecionar os índices familiares de orientação. Cada um sabe que esse acomodamento é um regime dinâmico e que as insuficiências suscitam o mal-estar particularmente penoso para a manutenção primordial da pessoa.

Cada um o sabe, e isso é a marca do reconhecimento social desse regime. Não obstante, a personalização do fazer nesse regime o torna intangível ao outro e impede o gênero de coordenação que supõe as noções de ação social ou de prática social sobre as quais se assentam as Ciências Sociais. Esse fazer é desprovido de um sentido de orientação ao outro e também destituído de caráter coletivo. Os arranjos familiares desse outro nos são radicalmente estranhos, incompreensíveis, impossíveis de serem integrados no comum, na medida que nos parecessem somente desarranjos e desordens indescritíveis. O indescritível também contrasta com o modelo corrente de uma ação individual, revelando o quanto esse último modelo se encontra preparado para lidar com a vida em comum e a coordenação graças a um formato normal do "fazer com".

O regime de envolvimento no plano analisa a relação com o mundo preparado para uma certa construção do comum e uma coordenação que não supõe, finalmente, uma ação coletiva. Ele caracteriza o exercício de uma capacidade do indivíduo em realizar seu projeto sem se contentar com o tratamento exclusivamente subjetivo da vontade, nem mesmo o reduzindo à dimensão cognitiva da racionalidade. Mais do que uma ligação instrumental com relação ao mundo, tal como elaborado na tradição sociológica, esse regime de envolvimento nos ajuda a ver isso que a capacidade voluntária deve ao modelamento de um mundo que prevê a manutenção temporal do projeto, a partir de um arranjo funcional do meio envolvente. $\mathrm{O}$ bem garantido aparece, então, claramente no plano desse envolvimento, no qual a capacidade voluntária individuada padece 
de uma deficiência radicalmente experimentada aos olhos de uma autonomia, exigida por si e pelo outro.

O regime do envolvimento justificável pode derivar da análise anterior das exigências de justificações e das críticas legítimas desenvolvidas em (e no) público, tal como levada a cabo por mim e Luc Boltanski. A capacidade reconhecida como grandeza depende do agenciamento do meio envolvente a partir de seres qualificados para garanti-la. O bem resultante dessa dependência é uma especificação do bem comum. Ele governa a seleção e a avaliação do agente que se coloca à prova da dinâmica crítica das experimentações da realidade segundo essa grandeza.

Sem pretender ser exaustivo, esses três regimes elementares permitem distinguir as capacidades ou dignidades que são reconhecidas aos seres humanos, bem como colabora com a análise dos envolvimentos mutuais que repousam sob elas, permitindo decompor assim as arquiteturas da personalidade e da comunidade.

Tratando-se da pessoa, duas diferenças importantes devem ser notadas: a primeira diz respeito à maneira de introduzir o outro que reconhece. Sabemos que Honneth não se sustenta apenas sobre a arquitetura hegeliana, mas que ele recorre também ao interacionismo herdado da filosofia pragmatista americana, e, notadamente, à sociologia de Mead. Outros intervém, sem dúvida, a partir da afirmação da capacidade, todavia, a mutualidade do reconhecimento intersubjetivo só entra verdadeiramente em cena no terceiro estudo do percurso, após o reconhecimento-identificação e o reconhecimento da ipseidade.

Os regimes de envolvimento são concebidos como as relações com o mundo circundante e não diretamente com um outro, como tratado habitualmente pela perspectiva sociológica. O motivo desta virada abrange a preocupação de relacionar os modos de ser agente, dos poderes às modalidades de interdependência, ao olhar de um ambiente apropriado, que garante a confiança e que é "experimentado" como tal. Os diversos modelos correntes da ação, da escolha racional até a teoria da prática, não alcançam esta interdependência nem seus benefícios, 
porque eles polarizam a atenção em torno do sujeito, tornando-o inconsciente. A virada pela relação com o mundo envolvente está longe de rejeitar a questão do reconhecimento. Os regimes envolvem, de fato, os bens comumente reconhecidos que, por conseguinte, não são necessariamente compartilhados nos quadros de ação. Por definição, num regime são frequentemente reconhecidos não só os bens comuns que asseguram a conformação da grandeza das pessoas num envolvimento justificável com o mundo propriamente qualificado, mas também a felicidade do exercício da individualidade em um universo, cuja disposição funcional do meio envolvente, se conforma pelo regime do plano. Até mesmo na conveniência íntima, procurada pelos vínculos com o entorno familiar - o qual confere seu fundamento primordial à pessoa -, reside radicalmente estranha ao ser não íntimo. Isto é, os regimes são comumente reconhecidos como servindo a todo e qualquer um para apropriar as condutas de modo congruente, porque eles oferecem quadros de reconhecimento da pessoa segundo uma pluralidade das suas capacidades. A virada pelas interdependências não é inconsequente. A elucidação de uma relação com o mundo garante a capacidade reconhecida à pessoa e nos permite compreender a opressão que se abate gravemente quando essas interdependências são afetadas.

Uma segunda diferença significativa dá lugar à linguagem. Ricoeur aborda as capacidades do ser humano a partir da palavra [parole]. Não que ele ignore o outro lado da linguagem, que é colocado em jogo por outras fenomenologias e abordado notadamente na sua proposta sobre a ternura e o erotismo (RICOEUR, 1967). Mas ele escolheu, como método, se ater naquilo que se elabora a partir da linguagem. Honneth toma, em contrapartida, suas distâncias ao olhar de uma linguagem que encontra um lugar muito eminente nas ciências sociais. Isto porque ele explora um outro lado do agir comunicacional segundo Habermas no reconhecimento do amor. Quanto à análise dos regimes de envolvimento, elucida um status muito diferente da linguagem de um ao outro. No regime de envolvimento justificável, a linguagem controlada importa para a qualificação ainda que a prova de realidade não se reduza. Em resumo, nos quadros de justificação ou de crítica, as qualidades estão garantidas assim como as relações dos seres qualificados, a linguagem é compelida 
à formalidade convencional da designação codificada das qualidades. A partir de outros regimes uma tal utilização é desacreditada como cantilena.

Para dar conta do envolvimento no plano, a linguagem ordinária da narrativa é perfeitamente adequada, com seus verbos de ação, seu sujeito voluntário e seu complemento do objeto. As designações não são, então, convencionalmente controladas. Elas garantem uma margem importante de tolerância, o envolvimento pode ser relacionado ao outro, ou, incluir a si mesmo sem dificuldade aparente à pretensão da garantia pública. No envolvimento familiar, a utilização da linguagem é ainda outra. Longe da argumentação e da narrativa, ela não serve mais do que para mostrar, pelos deícticos, o ajuste mais próximo possível dos seres em torno dos quais a linguagem sinaliza mais do que denota. A língua se mistura ao gesto pelas expressões não articuladas.

\section{A GRANDEZA DO ENVOLVIMENTO JUSTIFICÁVEL E A ESTIMA SOCIAL}

Axel Honneth explica a esfera do reconhecimento como sendo regida pela estima social, enfatizando-a nas continuidades e rupturas com a figura da honra nas sociedades divididas em estamentos. Ele cita Max Weber, em Economia e Sociedade, relacionando a "honra estamental" à exigência de se adequar a um modo de vida específico para aqueles que desejam pertencer a uma esfera particular. Honneth sublinha que o valor do status é socialmente definido a partir da percepção conferida aos "fins da sociedade". A consideração social é coletivamente atribuída ao status, segundo uma "tipologia cultural" das relações assimétricas entre os grupos sociais. No interior do "pensamento pós-convencional", em compensação, "o sujeito é introduzido na qualidade de uma grandeza dotada de uma história individual” no campo da estima social, nas interações horizontais e simétricas entre indivíduos autônomos, vinculados a certos horizontes de valor.

Antes de abordar os comentários críticos feitos por Paul Ricoeur, gostaria de considerar que a gramática comum às ordens de grandeza sugere um 
terceiro termo para relacionar a oposição que separa habitualmente, no domínio das ciências sociais e políticas, as antigas sociedades estamentais, e as sociedades modernas, marcadas pela realização individual. Esta consideração me conduz a situar as grandezas no seio de uma variedade de apreciações, podendo servir para cultivar uma estima social. Em contrapartida, nos beneficiamos de uma elucidação original na "grandeza individual”, para retomar a fórmula de Honneth. As grandezas não apresentam apenas uma tipologia cultural de valores. Elas colocam na ordem do dia o modelo comum que lhes corresponde, o qual explicita uma certa gramática do senso de justiça. Nós mostramos, com Luc Boltanski, como esta gramática deveria amenizar a tensão entre duas exigências principais: aquela de uma humanidade comum, de uma dignidade igualitária dos seres humanos; e aquela da ordem de uma apreciação que estabelece, necessariamente, os estamentos hierárquicos. Duas condições são requeridas para esta amenização. A primeira é que as grandezas não sejam fixadas permanentemente às pessoas, à diferença dos status coletivos estáveis, como supõem os estamentos do antigo regime. A prova de qualificação [épreuve] deve ser retomada, caso contrário, um forte sentimento de injustiça encontrará lugar para se manter. A segunda condição exige que o valor daquilo que é grande se apoie no bem comum, no sentido de que a grandeza dos estados dos "grandes" beneficiará os estados "menores". Na ausência de um suporte convincente, a "ideologia", no primeiro sentido desta construção ideal, suscita uma traição enquanto "ideologia", no segundo sentido adotado na crítica.

Os estados de grandeza não são, então, associados aos coletivos particulares, mas a uma maneira de procurar uma humanidade comum. O sujeito não está qualificado porque ele é membro de um círculo, e sim porque ele é mais coletivo que outros sujeitos em relação a uma ordem de grandeza. As grandezas não se vinculam às especificidades das diferenças culturais nesse caso, mas propõem a ultrapassagem validada pela humanidade. Bem compreendida, esta pretensão é limitada à aceitação das exigências primordiais que fundamentam o modelo comum e que são desigualmente colocadas à frente, de acordo com contextos culturais e históricos. 
Ressaltamos que o emprego do termo "pós-convencional" tem o perigo de ignorar o aspecto formalmente convencional da qualificação, o qual destacamos na linguagem da justificação ou no tratamento quase cerimonial dos "grandes momentos" que manifestam os superiores comuns e suas instituições. Ricoeur se preocupa, inclusive, com uma simplificação excessiva da complexidade da passagem à modernidade, que resulta da ruptura entre a estima da etapa convencional e o respeito da etapa pós-convencional, barrando a retirada da parcela da estima da estima social.

A análise das grandezas, seguida dos envolvimentos de mínima publicidade, permitem elucidar a fórmula de uma "grandeza do indivíduo" sem pretender que esta se associe à gramática das grandezas.

A fórmula é particularmente bem adaptada àquilo que designarei como o "indivíduo-para-o-público" sobre a qual se apoia a gramática liberal do público. Um tal "estado" de indivíduo é requerido para compor um bem público, com outras pessoas no mesmo estado, sob o custo do sacrifício das vinculações mais pessoais e íntimas, com a finalidade de uma expressão desta individualidade pública em termos de opiniões discutíveis e interesses negociáveis. Este estado supõe uma elevação do tratamento dos elementos da "história individual do sujeito", como Honneth propõe em seguida, com a finalidade de transformá-los em opiniões e interesses aceitáveis para os procedimentos de composição do público.

A gramática do liberalismo político difere daquela das grandezas, na qual se ignoram os bens comuns que se encontram além do público liberal. Ela coloca em oposição o avanço dos procedimentos de composição deste público a partir da voz dos indivíduos modelados para o público, procedimentos esses que supõem que os bens sejam reduzidos ao estado de preferências individuais. Ao contrário, a gramática das grandezas sustenta uma forma de bem comum para uma humanidade comum, a composição entre múltiplas grandezas passa pelos compromissos limitados no tempo e no espaço, equipado para uma certa estabilidade. O modelo comum das grandezas permite compreender a capacidade de compromisso de um e outro, mesmo no caso em que eles estejam numa relação crítica. Este último ponto nos conduz ao comentário crítico presente nas contribuições de Ricoeur. 
Ricoeur não sugere somente diferenciar, a partir das ordens de grandeza, as modalidades do reconhecimento pela estima social segundo Honneth, com a finalidade de dar precisão às condições de um "pluralismo axiológico". Ele indica como a crítica pode "estimular cada ator de um mundo aos valores de um outro", deixando de transitar entre mundos, num aprendizado que, tal como numa língua estrangeira, permite perceber a sua própria língua como uma entre outras. Ricoeur deduz como a capacidade do compromisso "abre o acesso privilegiado ao bem comum". Ele concebe também o bem comum como aquele de uma comunidade humana particular, que deve combinar com esta variedade de grandezas, e não como um bem comum específico, válido para a toda a humanidade. O modelo das grandezas, de fato, não leva em consideração as condições de manutenção de uma comunidade particular, ainda mesmo na sua definição, a qual é orientada em torno de uma humanidade comum. Ricoeur assinala que a adequação ao compromisso permite relativizar a interação com uma grandeza, e que lhe corresponde "na proximidade das pessoas", a capacidade de "reconhecer-se como uma figura da passagem de um regime de grandeza a um outro, sem se deixar confinar na oscilação entre o relativismo desiludido e a acusação panfletária". Ele menciona, para esta ocasião, a "capacidade de phrónesis ${ }^{7}$ [sagesse phronétique], que não separa a justiça da justeza" na busca da "ação que convém" (RICOEUR, 2004, p. 299-307). Esta última proposição remete àquilo que figura na passagem dos envolvimentos de mínima publicidade às convenções coletivas, à convenção do plano ou às conveniências pessoais do familiar, na qual a integração contribui para dar consistência à pessoa (THÉVENOT, 2006, p. 241-265).

Axel Honneth insiste na "solidariedade" que viu nascer as "relações de estima simétrica" garantidas pelos valores comuns. No entanto, a qualificação no seio de um mundo não estabelece somente um reconhecimento simétrico e

\footnotetext{
[N.T.] A capacidade ou habilidade de "phrónesis" ou "phronétique" é aquela de identificar características (de situações) particulares. Para mais sobre o assunto ver: CARVALHO, Helder Buenos Aires. A phrónesis aristotélica: breve comparação das leituras de Alasdair Macintyre e Paul Ricoeur. HYPNOS, n. 27, p. 260-283, 2011; ou GREISCH, Jean. Vers quelle reconnaissance? Revue de Métaphysique et de Morale, v. 2, n. 50, p. 149-171, 2006.
} 
mútuo de pertencimento a ele. A prova se constitui numa certa hierarquia ("os grandes abrangem os pequenos") que afeta a questão da autoridade. Ricoeur enfatiza justamente que os aspectos importantes da autoridade institucional são ignorados no De la justification. Assim, é na inscrição da autoridade no tempo, segundo a figura fundamental importada pela razão de que "em nenhum poder são asseguradas a estabilidade e a duração, caso ele não consiga capitalizar para o seu benefício o histórico anterior da autoridade” (RICOEUR, 2001, p. 122). Porém eu quero seguir o caminho da "hierarquia" e da sua "verticalidade”. A partir do primeiro estudo sobre o reconhecimento-identificação, Ricoeur nota sutilmente como o "reconhecimento-adesão do 'ter por verdade' comporta um 'valor a mais', no qual a admissão não acontece sem evocar uma dimensão de elevação" (RICOEUR, 2004, p. 308). Me inclino a pensar que este "valor a mais" da identificação é exaltado na relação hierárquica entre a categoria e os itens que a compõem, ou entre o "bom" representante, tal como ele aparece nas pesquisas experimentais, desde o João de barro ${ }^{8}$ que é mais João de barro até o trabalhador que é mais trabalhador (BOLTANSKI; THÉVENOT, 1983). Esta hierarquia me parece estar no coração do movimento que nós seguimos, da representação cognitiva à representação simbólica, às ordens de avaliação segundo as grandezas.

Paul Ricoeur considera o "reconhecimento de superioridade" que Hans-Georg Gadamer dissocia da obediência, propondo que a noção de grandeza esteja próxima desta ideia. Ele nos aproxima, então, de uma circularidade entre a superioridade da grandeza que nos aportamos a uma superioridade comum e "o ato do reconhecimento" que se manifesta na participação das provas de qualificação (RICOEUR, 2004, p. 309). Me parece que é preciso se atentar aos dois níveis da crítica, que pode ser analisada a partir do modelo das grandezas. A primeira é aquela da relação crítica de uma grandeza à outra. É aqui que a participação da prova numa ordem é, por definição, o reconhecimento da superioridade desta ordem. E é verdade que nada é dito no modelo de uma meta-integração das grandezas, disto que leva a

\footnotetext{
[N.T.] Optamos por traduzir "oiseau” (pássaro) como João de Barro pelo seu significado na cultura popular, associado diretamente ao trabalho.
} 
escolher entre uma ou outra, senão em termos de dispositivo de compromisso. Ao mesmo tempo, o segundo nível da prova não tem a mesma circularidade, já que ele se abre à retomada da qualificação, no interior de uma grandeza. Da mesma forma que, na relação entre mestre e discípulo, a grandeza se inscreve sempre em uma dependência mútua, quase assimétrica, o grande depende do menor para que se mantenha o mundo do qual ele extrai a sua grandeza; e o beneficiário menor, a princípio, depende dos investimentos do grande. Os repertórios de justificativas ou de críticas empregadas no curso das provas estabelecem tais dependências.

\section{O ENVOLVIMENTO NO PLANO, O RESPEITO PELO INDIVÍDUO E O DIREITO}

A segunda esfera especifica o reconhecimento bem como o respeito conferido ao indivíduo. Segundo a tripartição hegeliana, retomada por Axel Honneth, esta esfera se insere no direito. O domínio das trocas contratuais entre proprietários assegura uma generalização jurídica e formal das relações particulares, promovendo uma pessoa jurídica abstrata. Então o trabalho não permite, para Hegel, o "fazer-me-coisa" diante do instrumento e do produto, a inscrição jurídica leva ao "ser reconhecido abstratamente". Honneth viu a "base intersubjetiva" da vida social. George Herbert Mead, nos seus trabalhos, encontra um estágio regrado do jogo, dos papéis e das normas morais, que repousa no julgamento de um "outro generalizado" e no tratamento de si como "me". Ainda que Mead ilustre a sua proposta pela propriedade e se refira aos direitos morais reconhecidos em seu destino, notamos que a sanção jurídica não ocupa o mesmo lugar que em Hegel. Honneth nos mostra, sobretudo, um reconhecimento do outro generalizado que precede à formalização do direito.

Com a identificação de um regime de envolvimento em plano, a caracterização do indivíduo reconhecível difere. Enfatiza um ponto de partida evidente no terceiro regime de familiaridade, considerado mais à frente, no 
qual a mutualidade anuncia uma intimidade personalizada. Este regime não supõe nem a formalidade pública do direito, nem o julgamento de um "outro generalizado", na medida em que será colocado como fonte de julgamento legítimo. Este é o regime de envolvimento justificável, que visa as garantias do público e da sua legitimidade. O envolvimento no plano capta comumente a pessoa enquanto indivíduo, sem reivindicar o direito ou a justiça. Garante o poder da vontade individual na concretização de uma ação normal com os meios apropriados. O envolvimento no plano acentua a capacidade voluntária do indivíduo, constantemente conhecido como liberdade de escolha, dependente de uma formatação funcional do mundo. Os planos e funcionalidades são aqueles das ações normais, comumente identificáveis com uma ampla tolerância de execução, a diferença do regime precedente e das suas qualificações publicamente justificáveis. Mutualizado, o envolvimento no plano aporta o reconhecimento das individualidades autônomas, segundo uma relação simétrica ausente nas grandezas. Esta mutualidade se estende ao anonimato, à diferença daquele que repousa no envolvimento familiar. $\mathrm{O}$ regime no plano distingue no outro e em si mesmo, o poder da vontade individual, sem envolver o gênero da confiança que supõe uma intimidade pessoal ou as garantias do direito.

A identificação dos regimes é adquirida fora do direito. Ela permite, em contrapartida, elucidar a complexidade do equipamento jurídico que ampara o traço dos diferentes envolvimentos assim como as transformações inscritas num tratamento formal. Podemos reparar a potente armadura da figura de um indivíduo envolvido voluntariamente, a quem é nitidamente requisitado, anterior à convenção no sentido do contrato, e que é suposto no modo de fazer jurídico próprio da responsabilidade individual. Porém nós distinguimos também as justificações de bem comum metamorfoseadas em direitos individuais fundamentais, por vezes sob custo de expressivas distorções. Os conflitos entre justificações demandam o compromisso no julgamento, o qual se exprime no direito pela noção de "proporcionalidade". O envolvimento familiar é igualmente formalizado em certos tratamentos, não estritamente liberais, da apropriação das coisas, nas relações de uso e de vizinhança. 


\section{O ENVOLVIMENTO FAMILIAR E A CONFIANÇA GANHA NAS RELAÇÕES PRIMÁRIAS}

Axel Honneth relaciona a terceira esfera do reconhecimento à afetividade $^{9}$ e nota que, neste ponto, não encontramos em Mead um estado de reconhecimento mútuo comparável àquele identificado por Hegel. Honneth, também, recorre à psicanálise de Donald Winnicott para caracterizar uma "intersubjetividade primária" própria desta terceira esfera de "relações eróticas, amigáveis ou familiares" que implicam "os lugares afetivos potentes entre um número restrito de pessoas". Enquanto Winnicott afirma que a capacidade de ficar sozinho é garantida num processo de desapego da unidade indiferenciada mãe-filho, "matéria a partir da qual se forma a amizade", Honneth busca a repercussão da fórmula hegeliana do amor: "ser si-mesmo no estrangeiro". Ricoeur se detém também na dialética de presença e da ausência relacionando a proposta de Simone Weil nas duas formas insolúveis da amizade e os dois desejos dos amantes e dos amigos: "Um de se amar tanto que entre um no outro e não sejam mais que um; e o outro, de se amar tanto que tenham entre eles a metade do globo terrestre, sem que esta união sofra algum encolhimento". A partir da falta provada pelo amante, Ricoeur escreve que "para quem é traído, as esperas são mais complexas do que aquelas relativas à simples integridade física" (RICOEUR, 2004, p. 279) e ele emprega sua fórmula suprema: "aprovar mutuamente a existência".

A aprovação mútua dos amantes não consiste ela mesma em uma dupla dissimetria? A dependência é assimétrica sob o olhar do ser que você reconhece mais que a si mesmo, ali onde você não se conhece antes deste encontro, $\mathrm{e}$ que você aprova enquanto lhe dá consistência. É desta dependência assimétrica que resulta a profundidade da humilhação que Ricoeur relaciona à retratação ou recusa da aprovação. Não devemos então conceber o reconhecimento do amor como a superposição de duas dependências assimétricas, que depreciam a

[N.T] "Aimant", no original. Apesar de poder denotar tanto "afetividade" quanto "amorosidade", preferimos a primeira acepção tanto para aproximá-la do conceito de ágape mobilizado por Ricoeur no livro Os percursos do reconhecimento, quanto para evitar restringir esta esfera do reconhecimento ao conceito de amor romântico. 
temática da fusão? O esquecimento da "intransponível diferença” entre um e outro não se esquece também das assimetrias que a ideia de reconhecimento "horizontal" corre o risco de mascarar? Esta dupla assimetria nos desvia do gênero de autonomia expresso na vontade individual, à qual nos reportamos anteriormente no regime de envolvimento no plano, e a qual o direito e os direitos instituem. É nessa dupla assimetria, instituída pela família, que este reconhecimento toma também um caminho diferente, tanto em Hegel quanto em Honneth.

A análise do envolvimento familiar com o entorno, o qual reside aquém de toda mutualidade particularmente amorosa, nos é elucidada na dupla assimetria. Dando atenção ao fundamento do íntimo da pessoa, que mantém seus vínculos e suas dependências mais familiares, e à radicalidade estrangeira de um olhar familiar a outrem, se apreendem melhor as condições de uma abertura excepcional às singularidades estranhas de uma outra pessoa, o que é experimentado na aprovação amorosa e o que é penoso na sua retirada. Para dar lugar a um outro familiar, se for estranho, é necessária a potência de um tipo de desenvolvimento que os seres humanos elaboram até identificar em comum o envolvimento próprio do desejo. O seu penhor mantém uma dependência em relação ao atrativo que é viciado, enquanto tal dependência demanda o ser experimentado novamente. Sem mesmo recorrer à pesquisa própria da psicanálise, nem ao seu quadro teórico, a modalidade do apelo da mercadoria mostra uma semelhança com o envolvimento do desejo, ao solicitar uma nova elaboração destinada a construir um envolvimento público mercantil, contratualizado por um objeto identificado em comum.

\section{CONCRETIZAÇÃO DOS RECONHECIMENTOS: SEGUNDO A NOVA TEORIA CRÍTICA, AS FORMAS DE EXPERIMENTAR O ENVOLVIMENTO, A VULNERABILIDADE DO HOMEM CAPAZ}

O sucesso da temática do reconhecimento nas ciências sociais e políticas, bem como a sua utilização extensiva para o fazer político ou de gestão, 
convidam a perguntar acerca dos projetos ideológicos que podem se apropriar dela e modelá-la. Ela pode servir para livrar-se da denúncia das ciências sociais críticas, bem como das inquietações críticas e das preocupações pela opressão trazidas atualmente pela sociologia da crítica e seus recentes desdobramentos. Ao contrário, ela pode ser apropriada pela sociologia crítica da dominação, na qual se oferece uma reconversão simples das suas propostas em tantas negações de reconhecimento. Nenhuma das suas utilizações faz jus à originalidade do projeto de Honneth e de uma nova teoria crítica. Preservando-se de uma "hermenêutica da suspeita sempre demasiadamente certa do seu assunto", Honneth se dispõe a "diferenciar as formas ideológicas das formas justificadas do reconhecimento" ao observar, muito apropriadamente, que a "concretização" do reconhecimento não toma as mesmas formas no caso das interações simples e naquelas que dizem respeito ao reconhecimento generalizado (HONNETH, 2006, p. 271-273). Esta preocupação adere nossa atenção às condições em que se colocam à prova as justificações e críticas, bem como, aos desdobramentos da análise das maneiras de provar a concretização dos bens envolvidos nos regimes de menos publicidade. Aos diferentes modos de reconhecimento correspondem tantas maneiras de prova dos benefícios associados, quanto tantas modalidades de provar quando o envolvimento falta e a expectativa desaponta. No segundo encontro do Institut für Sozialforschung [Instituto para Pesquisa Social] e do Grupo de Sociologia Política e Moral, acontecido em Frankfurt no mês de novembro de 2006, Axel Honneth declarou que partilhamos uma mesma oposição à crítica externa, mantida por uma certa sociologia crítica, e uma mesma atenção à crítica interna, arraigada na sociedade, quebrando, ao mesmo tempo, a unidade da crítica acadêmica.

O olhar de Ricoeur acerca dos reconhecimentos não corre o risco nem de cair no idealismo, o qual é regularmente tido como contraintutivo, nem na suspeita de ter produzido uma análise tão famosa. A sua filosofia não se desenvolve no fundamento do homem capaz - dizer, fazer, relatar ou (se) exibir -, tomando a medida das suas insuficiências e vulnerabilidades. A diligência se alimenta das preocupações por estas vulnerabilidades. 
Devo acrescentar que o movimento que ele imprime na sua filosofia moral no "si mesmo como um outro", da visão ética à norma moral, e da norma moral à habilidade prática, chama a nossa atenção à integração entre as diferentes esferas do reconhecimento. Um permite reconhecer aquilo que o outro não saberá aprovar. Assim, a "habilidade prática consiste em inventar as condutas que satisfarão ao máximo a exceção que demanda a solicitude, traindo a regra o mínimo possível” (RICOEUR, 2004, p. 312).

\section{EPÍLOGO EM ALEGORIA}

A alegoria representa a ideia abstrata de um ser animado, envolvido numa reconciliação com o espectador que não permite a abstração. Ela não atua como substituição e sim como uma composição integrante de múltiplas formas de conhecer, reconhecer e de abrir uma passagem apaziguada entre seus respectivos envolvimentos.

Em gratidão pela expedição aos Percursos do reconhecimento e do entusiasmo por eles proporcionado, minha carta ao autor é escrita na clareza do reconhecimento. Iluminando o escritório, duas corolas de vidro projetam a luz numa jovem mulher envolvente que avança no porvir, com pés nus e passo sereno. Um véu se molda às suas formas, banhando-a pelo ritmo vívido do seu andar, deixando descoberta a sua perna esquerda que levanta o drapeado no seu ímpeto, descobrindo seus ombros e meio seio despido. Com a cabeça virada, olha de lado para um evento a reconhecer, uma caneta é erguida, prestes a ser estabilizada. Na outra mão, um maço de folhetos, nos quais se lê a frase "o reconhecimento é a lembrança da dádiva". Os arabescos do corpo apelam ao amor que prova peculiarmente. Mas a caneta projetada no ato, o maço e a sua máxima dizem mais do que a sua projeção, e até mesmo que o código que reconhece por direito. Comprimido com o maço, um ramo de louro expande o reconhecimento pela estima social. 


\section{REFERÊNCIAS}

1. BOLTANSKI, Luc; THÉVENOT, Laurent. Finding one's way in social space; a study based on games. Social Sciences Information, v. 22, n. 4-5, p. 631-680, 1983.

2. BOLTANSKI, Luc; THÉVENOT, Laurent. De la justification: les économies de la grandeur. Paris: Gallimard, 1991.

3. HONNETH, Axel. La Lutte pour la reconnaissance. Tradução: Pierre Rusch. Paris: Éditions du Cerf, 2002.

4. HONNETH, Axel. La Société du mépris: vers une nouvelle théorie critique. Tradução: Olivier Voirol, Pierre Rusch, Alexandre Dupeyrix. Paris: La Découverte, 2006.

5. RICOEUR, Paul. Sexualité, la merveille, l’errance, lénigme. In: RICOEUR, Paul. Histoire et vérité. Paris: Le Seuil, 1967.

6. RICOEUR, Paul. Soi-même comme un autre. Paris: Le Seuil, 1990.

7. RICOEUR, Paul. Le paradoxe de l'autorité. In: RICOEUR, Paul. Juste 2. Paris: Éditions Esprit, 2001.

8. RICOEUR, Paul. Parcours de la reconnaissance: trois études. Paris: Stock, 2004.

9. THÉVENOT, Laurent. L’Action au pluriel: sociologie des régimes d’engagement. Paris: La Découverte, 2006.

10. THÉVENOT, Laurent. La acción en plural. Una introducción a la sociología pragmática. Buenos Aires: Siglo Veintiuno Editores, 2016. 